\title{
Acute response of intermittent and continuous aerobic exercises on blood glucose of adolescents with type I diabetes
}

\section{Resposta aguda do exercício aeróbio intermitente e contínuo na glicemia de adolescentes com diabetes tipo 1}

Valderi Abreu de Lima'; Luis Paulo Gomes Mascarenhas'; Juliana Pereira Decimo'; William Cordeiro de Souza²; Suzana Nesi França'; Neiva Leite

\begin{abstract}
The purpose of the study was to investigate the acute effect of continuous and intermittent aerobic exercise on blood glucose of adolescents with type 1 diabetes. A cross-sectional analysis of eight adolescents with type 1 diabetes mellitus between 10 to 15 years. Variables such as body mass, height, body mass index $\mathrm{z}$ score, glycated hemoglobin and cardiorespiratory fitness were assessed. There were two tests on a cycle ergometer: 30 minutes of continuous exercise and 30 minutes of intermittent exercise. Blood glucose was measured before and after the exercises and lactate concentration was measured at the end of the exercise. Student's t test and Pearson's correlation were used, considering $\mathrm{p}<0.05$. In the continuous exercise proto$\mathrm{col}$, there was a significant difference in pre- and post-exercise blood glucose levels ( $p=0.048$ ), whereas the intermittent exercise protocol did not show statistically significant differences in blood glucose. Higher concentrations of lactate were found after the intermittent exercises $(\mathrm{p}=0.036)$. There was a strong correlation between glycemic control and body mass index $\mathrm{z}$ score $(r=0.893 p=0.041)$. Regarding the other variables, there were no significant correlations. The reduction in blood glucose was lower after intermittent aerobic exercises, compared with continuous exercises, which could be an interesting strategy to prevent acute exercise-induced hypoglycemia.
\end{abstract}

Keywords

Diabetes; Exercise; Hypoglycemia.

\section{Resumo}

O objetivo desse estudo foi verificar a influência aguda do exercício aeróbio contínuo e intermitente na glicemia de adolescentes diabéticos tipo 1. Estudo transversal, que avaliou oito adolescentes com Diabetes Mellitus Tipo 1, entre 10 a 15 anos. Avaliaram-se a massa corporal, estatura, indice de massa corporal score z, hemoglobina glicada e capacidade cardiorrespiratória. Realizaram-se dois testes em cicloergômetro, 30 minutos de exercícios contínuos e 30 minutos intermitentes. A glicemia foi mensurada antes e após a realização dos exercícios e a concentração de lactato mensurado ao final do exercício. Utilizou-se o teste T de student, e correlação de Pearson, considerando-se $p<0,05$. Observou-se diferença significativa entre os valores de glicemia antes e após o exercício contínuo $(p=0,048)$, no intermitente não houve diferença significativa na glicemia pré e pós-exercício $(p=0,160)$. Maiores concentrações de lactato foram encontradas após os exercícios intermitentes $(p=0,036)$. Há forte correlação entre o controle glicêmico avaliado por meio do teste de hemoglobina glicada e o indice de massa corporal score $z$ ( $r=0,893$ $p=0,041)$. Com relação às outras variáveis não houve correlações significativas. O declínio na glicemia é menor ao realizar exercícios aeróbios intermitentes comparados com exercícios contínuos, o que pode ser uma interessante estratégia para prevenção de hipoglicemia aguda induzida pelos exercícios.

Palavras-chave

Diabetes; Exercício; Hipoglicemia.

\section{Introduction}

The treatment of individuals with type 1 diabetes and good glycemic control depend on several factors, such as nutrition, insulin-therapy and physical activity $^{1}$. Physical activity plays an important role in the

1 Federal University of Paraná (UFPR). Curitiba, PR, Brazil.

2 Contestado University (UnC). Canoinhas, SC, Brazil. health of type 1 diabetics. Additionally, it is directly associated with the increase in cardiorespiratory fitness and reduction in insulin doses ${ }^{2}$.

However, despite all the benefits of regular physical activity practice, there is an important limiting factor for adherence: the fear of exercise-induced hypoglycemia that can occur during, immediately after or hours after exercising ${ }^{3}$. 
Intermittent exercises are one type of exercise, whose main characteristic is the variation in intensity during practice, with the inclusion of maximum and short sprints alternated with resting periods or lower intensities. These metabolic characteristics are similar to those of the majority of sports commonly practiced, such as soccer and volleyball ${ }^{4-5}$ and spontaneous child games ${ }^{6}$. This practice seems to be a positive alternative to the reduction in the risks of exercise-induced hypoglycemia, compared to continuous exercises ${ }^{7}$ and lower risk of nocturnal hypoglycemias ${ }^{8}$.

There are no guidelines based on evidence for the safe practice of high-intensity intermittent exercises and their effect on the blood glucose level of individuals with type 1 diabetes. This type of exercise characterizes the majority of sports games and spontaneous child games ${ }^{4,5,6}$. For this reason, blood glucose behavior must be identified through two different exercise protocols (continuous and intermittent). Based on these elements, the present study aimed to observe the acute influence of continuous and intermittent exercise on the blood glucose level of adolescents with type 1 diabetes and to assess possible relationships among physical activity level, body mass index and glycemic control through the glycated hemoglobin test (HbA1c).

\section{Methods}

The present study had a cross-sectional design and assessed eight adolescents, four boys and four girls aged between ten and 15 years, with type 1 diabetes, who had been diagnosed at least two years before. The sample was obtained from patients cared for in the Diabetes Outpatient Clinic of the Pediatric Endocrinology Unit of the City of Curitiba Clinical Hospital (HCC).

The sample was selected by convenience, assessing patients who accepted to participate in the present study with the authorization of parents, after an Informed Consent Form was signed, in accordance with Resolution 196/96 from the National Health Council, and approved by the Research Ethics Committee of the Paraná Federal University, under number 44193214-7.0000.0096.

Participants visited the HCC's Pediatric Endocrinology Unit laboratory three times in the afternoon. The first visit aimed to obtain the anthropometric measurements. Height was measured with a portable vertical stadiometer (WCS ${ }^{\circledR}$, Brazil) with a $0.1 \mathrm{~cm}$ accuracy, assessed in centimeters $(\mathrm{cm})$ at the end of maximum inspiration. Body mass was assessed with a portable digital scale (Filizola ${ }^{\circledR}$, Brazil) in kilograms (kg). According to data on height and weight, body mass index was calculated $\left(\mathrm{kg} / \mathrm{m}^{2}\right)$, dividing body weight by the square of height and subsequently converting it to score $\mathrm{z}$ to BMI with the WHO AnthroPlus ${ }^{\circledR}$ software program (version 3.2.2).

The Glycated Hemoglobin test (HbA1c) was performed in study participants in the Pediatric Endocrinology Unit to assess glycemic control, using the immunoturbidimetric TurbiClin test. After fasting for 12 hours, a venous blood sample was collected by nurses of the Pediatric Endocrinology Unit itself and the sample was subsequently sent for chromatographic analysis.

During the first visit to the laboratory, the cardiorespiratory fitness test (VO${ }_{2}$ max) was performed using the $\mathrm{K} 4 \mathrm{~b} 2$ portable gas analyzer ${ }^{\circledR}$ (Cosmed), using Balke's adapted protocol in a cycle ergometer'.

Participants began the test in a Caloi cycle ergometer ${ }^{\circledR}$, (CLB 30 Premium Model) with a load of 25 watts and speed at $50 \mathrm{rpm}$. At every three minutes, 25 watts were successively added until an individual's maximum heart rate was reached, as proposed by Tanaka ${ }^{10}$, or as soon as they could not maintain the speed or load. 
After 48 hours, participants returned to the laboratory to have the continuous exercise test performed, when they rode for 30 minutes (total work without prior warm-up) in a cycle ergometer (Caloi®, CLB 30 Premium Model) with a load of $60 \%$ of $\mathrm{VO}_{2}$ max.

After another 48 hours, participants returned to the laboratory to have the intermittent test performed, when they rode for 30 minutes in a cycle ergometer with a load of $60 \%$ of $\mathrm{VO}_{2}$ max such as in the continuous test, although alternating it with five sprints at maximum intensity lasting ten seconds at every five minutes. In all tests, $15 \mathrm{~g}$ glucose gels were available for use, if participants had hypoglycemia during or after the tests.

In both tests (continuous and intermittent), capillary blood glucose was previously measured (five minutes before) using a Glucometer (OneTouch Ultra-Life Scan $\left.{ }^{\circledR}\right)$ and blood lactate concentration was measured at the end of the exercise using a Lactometer (Accutrend PLUS-Roche ${ }^{\circledR}$ ). All tests occurred one hour after insulin administration. Participants' insulin therapy did not change, with mean doses of $26.5 \pm 7.36$ units per day of insulin ( $1 \mathrm{ml}=100$ units) of prolonged action (Glargina) and doses of $7.5 \pm 3.41$ units per dose of ultra-fast acting insulin (Aspart and Lispro), both with the same beginning and time of action.

As a safety measure and way to avoid complications, if the result of participants' pre-blood glucose test was lower than $100 \mathrm{mg} / \mathrm{dl}, 15$ grams of fast-absorbing carbohydrates were provided, there was a break of 15 minutes, and a new observation was subsequently made, so that tests could begin ${ }^{27,28}$.

If the blood glucose level was higher than $200 \mathrm{mg} / \mathrm{dl}$, a ketone test was performed with the FreeStyle ${ }^{\circledR}$ Optium Neo device. If the result was negative (lack of ketone bodies), the test would begin; if the result was positive, this test was not performed ${ }^{27,28}$.

Meals were individually standardized by a nutritionist prior to tests, with a portion totaling from $20 \%$ to $35 \%$ of the daily energy requirements and, of these, between $50 \%$ and $55 \%$ were comprised of carbohydrates according to the Recommended Dietary Allowance $(\mathrm{RDA})^{12}$. Procedures were performed in the following order: insulin administration, meal, and tests after one hour of insulin application.

Statistical analysis was conducted with the SPSS software program for Windows, version 22. Data on sample characterization included descriptive statistics with mean and standard deviation. Student's T-test was performed for the variables of glycemic variation. Pearson's correlation was used for the body composition variables, $\mathrm{HbA1c}$, BMI Z-score and $\mathrm{VO}_{2}$ max. A significance level of $\mathrm{p}<0.05$ was used in all analyses.

\section{Results}

The general characteristics, anthropometric data, $\mathrm{HbA} 1 \mathrm{c}$ and $\mathrm{VO}_{2}$ max of study participants are shown in Table 1. The adolescents assessed were categorized as eutrophic when they showed a BMI Z-score between -2 and +1 , according to the World Health Organization (WHO) classification ${ }^{11}$.

The blood glucose level assessed before and after exercises shows a higher mean reduction in this level when performing continuous aerobic exercises $(-85.22 \pm$ $31.55 \mathrm{mg} / \mathrm{dl})$, when compared to the intermittent exercise protocol $(-39.2 \pm 21.92$ $\mathrm{mg} / \mathrm{dl}$ ). Table 2 shows the results of glycemic means before and after exercises were performed and blood lactate values were obtained. There was a significant difference in glycemic values before and after continuous exercises with a mean reduction in the initial blood glucose level of $-26.48 \%$. A significant difference was 
also found in lactate values with higher concentrations after intermittent exercises $(\mathrm{p}=0.036)$.

TABLE 1 - Characteristics of the sample of adolescents with type 1 diabetes Curitiba, PR, $2016(n=8)$

\begin{tabular}{lc}
\hline & Mean/SD \\
\hline Age (years) & $13.81 \pm 2.00$ \\
Total body mass (kg) & $51.64 \pm 13.02$ \\
Height (cm) & $154.82 \pm 8.54$ \\
$\mathrm{HbA1c}(\%)$ & $9.60 \pm 1.33$ \\
$\mathrm{BMlz}$ & $0.62 \pm 1.03$ \\
$\mathrm{VO}_{2} \max$ & $37.11 \pm 9.21$ \\
\hline
\end{tabular}

$\mathrm{SD}=$ Standard Deviation; HbA1c= Glycated Hemoglobin Test; BMlz= Body Mass Index Z-Score; $\mathrm{VO}_{2} \max =$ Cardiorespiratory Fitness.

TABLE 2 - Differences in blood glucose and lactate after exercise.

\begin{tabular}{lcccc}
\hline & $\begin{array}{c}\text { Mean/SD } \\
\text { Pré exercise }\end{array}$ & $\begin{array}{c}\text { Mean/SD } \\
\text { Pós exercise }\end{array}$ & $\Delta$ variation & $P$ \\
\hline $\begin{array}{l}\text { Blood glucose cont } \\
(\mathrm{mg} / \mathrm{dl})\end{array}$ & $264.40 \pm 33.90$ & $194.40 \pm 55.17$ & $-85.2 \pm 31.55$ & $0.048^{*}$ \\
$\begin{array}{l}\text { Blood glucose pre inter } \\
(\mathrm{mg} / \mathrm{dl})\end{array}$ & $185.80 \pm 78.61$ & $150.80 \pm 64.37$ & $-39.2 \pm 21.92$ & 0.160 \\
$\begin{array}{l}\text { Lactate cont }(\mathrm{mmol} / \mathrm{l}) \\
\text { Lactate inter }(\mathrm{mmol} / \mathrm{l})\end{array}$ & & & \\
\hline
\end{tabular}

*Pre Cont= Pre-continuous exercises; Pre Inter=Pre-intermittent exercises; Pos Cont=Post-continuous exercises; Pos Inter=Post-intermittent exercises; $p<0.05$. ${ }^{*}$ Significant difference between lactate after continuous exercise and post intermittent exercise $\mathrm{p}<0.05$.

Pearson's correlation coefficient values among anthropometric measures (BMIz), HbA1c and $\mathrm{Vo}_{2}$ max are shown in Table 3. The glycemic control assessed through the HbA1c test has a significant direct relationship with the BMI Z-score $(r=0.893 p=0.041)$. There were no significant correlations among the other variables.

TABLE 3 - Relationship between variables age, height, HbA1c, body massindex Z score and cardiorespiratory fitness

\begin{tabular}{lccc}
\hline & HbA1c (\%) & BMlz & $\begin{array}{c}\text { VO max } \\
(\mathrm{ml} / \mathrm{kg} \cdot \mathrm{min})\end{array}$ \\
\hline Age (years) & -0.255 & 0.170 & 0.375 \\
Height(cm) & -0.126 & 0.266 & 0.377 \\
HbA1c (\%) & & $0.893^{*}$ & -0.564 \\
BMlz & & & -0.520 \\
\hline
\end{tabular}

$\mathrm{HbA} 1 \mathrm{c}=$ Glycated Hemoglobin Test; $\mathrm{BMI}=$ Body Mass Index Z-Score; $\mathrm{VO}_{2}$ max= Cardiorespiratory Fitness. ${ }^{*} p<0.05$.

\section{Discussion}

Regular physical activity practice results in improvements in cardiorespiratory fitness $\left(\mathrm{VO}_{2} \max \right)$ and the body composition of patients with diabetes ${ }^{12-13}$. Metabolic balance in individuals with diabetes includes the following three factors: insulin therapy, healthy eating and regular physical activity practice ${ }^{14}$. During aerobic exercises, skeletal muscles increase glucose consumption to generate energy. This decreases hepatic glycogenesis, leading to a reduction in blood glucose level and increase in the risk of hypoglycemia ${ }^{26}$. 
Moderate-intensity activities lead to continuous glucose consumption and their storage (muscle glycogen) and result in the use of glucose and free fatty acids as energy sources ${ }^{29,30}$. When high-intensity exercises are performed, the production of counter regulatory hormones is strengthened during activity ${ }^{30}$.

A reduction in blood glucose level was found after continuous exercises $(\mathrm{p}=0.048)$, although the same results were not observed after intermittent exercises $(\mathrm{p}=0.160)$. Data revealed a significant reduction in blood glucose level in the continuous exercise protocol, with a difference in initial mean blood glucose level of $26.48 \%(\Delta=-85.2 \pm 31.55 \mathrm{mg} / \mathrm{dl})$. In contrast, in the intermittent exercise proto$\mathrm{col}$, this reduction was not significant, totaling $18.84 \%(\Delta=-39.2 \pm 21.92 \mathrm{mg} / \mathrm{dl})$.

Studies with diabetics show contradictory results. The results of a study conducted by Guelfi, Jones and Fournier ${ }^{15}$, evaluating seven individuals with type 1 diabetes, found a lower decrease in blood glucose level when intermittent exercises were performed, when compared to continuous exercises. A study was performed with 11 diabetic athletes using two methodologies with different exercises: first, individuals exercised for 45 minutes at $40 \%$ of $\mathrm{VO}_{2}$ max interspersed with nine sprints of maximum intensity for 15 seconds; second, continuous exercises were performed with the same intensity and duration. The results of this study did not reveal differences between both exercise methodologies, thus diverging from the present study. Nonetheless, authors suggest that intermittent activity seems to be a protective factor against nocturnal hypoglycemia ${ }^{8}$.

This lower decrease in blood glucose level found in the present study suggests that intermittent exercises can be a valid strategy to prevent exercise-induced hypoglycemia. The study performed by Guelfi, Jones and Fournier ${ }^{16}$ compared the risk of hypoglycemia after intermittent exercises, including a control group that did not perform any exercises. The results of this study showed that, after exercising, blood glucose levels remained stable, whereas it continued to decrease in the control group, revealing that intermittent exercises can help individuals with type 1 diabetes to achieve a normal blood glucose level.

A case study performed with two diabetic patients compared the effects of two protocols of exercises performed in a cycle ergometer on participants' glycemic response, also showing a lower glycemic reduction with the practice of intermittent exercises, when compared to continuous aerobic exercises ${ }^{17}$.

Guelfi, Jones and Fournier ${ }^{15}$ found that catecholamine levels, blood lactate and growth hormone $(\mathrm{GH})$ were higher after intermittent exercise protocols, thus explaining the lower reduction in blood glucose level found, as these hormones promote a higher production of endogenous glucose during exercises ${ }^{15}$.

The concentration of blood lactate was assessed at the end of exercises and higher values were found in the intermittent exercise protocol $(\mathrm{p}=0.036)$. This increase in lactate concentrations could have promoted the lower reduction in blood glucose level observed, as part of the lactate produced is reused to produce aerobic energy, thus saving blood glucose ${ }^{18}$.

Interesting results were observed in the study performed by Dubé and Weisnagel ${ }^{19}$, where all high-intensity intermittent exercises increased the concentration of counter-regulatory hormones (adrenaline, glucagon, cortisol and GH), contributing to prevent exercise-induced hypoglycemia in individuals with type 1 diabetes. These results are important, as the fear of hypoglycemia is the main limiting factor for regular physical activity practice, which is even present in individuals without a history of severe hypoglycemia ${ }^{20}$.

The best option to assess glycemic control in the medium to long term is 
through the assessment of HbA1c levels ${ }^{25}$. Satisfactory glycemic control can prevent acute and chronic symptomatology associated with hyperglycemia and hypoglycemia ${ }^{24}$. The patients evaluated do not have good glycemic control, as evaluated through the $\mathrm{HbA1c}$ levels $(9.60 \pm 1.33)$. According to the Brazilian Diabetes Association ${ }^{21}$, the aim for good glycemic control in children and adolescents is an HbA1c equal to or lower than $7.5 \%$.

Maintenance of good glycemic control is important, as there is a strong association between high HbA1c levels and the onset of late complications, in addition to values below $7.6 \%$ seeming to be sufficient to prevent microvascular complications for at least 20 years ${ }^{22}$. HbA1c levels were significantly and directly associated with the BMI Z-score. These results show the relationship between body weight and glycemic control, assessed through the HbA1c. Physical activities directly contribute to the maintenance of adequate levels of body weight and HbA1c of individuals with type 1 diabetes. As shown in a recent meta-analysis review, the results of the studies assessed revealed the potential benefits of physical activity for the HbA1c (mean difference of $-0.52,95 \% \mathrm{CI}$ from -0.97 to $-0.07 ; \mathrm{P}=0.02$ ) and $\mathrm{BMI}$ (mean difference of $-0.41,95 \% \mathrm{CI}$ from -0.70 to $-0.12 ; \mathrm{P}=0.006)^{23}$.

It is important to emphasize the fact that the results of the present study only applied to the reduction in blood glucose level immediately after the end of exercises, as there was no glycemic monitoring for a longer time during sessions or after activities ended.

The present study had some limitations, such as the small sample size, which could prevent the results from being generalized. Additionally, the sample was selected by convenience as it dealt with a specific disease. Thus, the location chosen for volunteer selection was restricted to outpatient clinics that care for children and adolescents with type 1 diabetes. Possible confounding variables such as blood catecholamine and GH levels were not assessed and this could explain the results found, in addition to the sexual maturation stage, which could have played a role. Another important point is that there was no randomization of continuous and intermittent exercise sessions and this could be a work bias and limitation (load effect). Consequently, future studies must be performed with the purpose of comparing different exercise protocols and determining the influence of high-intensity intermittent exercises on the glycemic response of children and adolescents with type 1 diabetes more effectively.

The present study showed that the reduction in blood glucose level is lower when intermittent aerobic exercises are performed, compared to continuous exercises, which can be an interesting strategy to prevent acute exercise-induced hypoglycemia. One should be aware of the fact that such result refers to blood glucose levels assessed immediately after the end of exercises. Therefore, data must be used with caution and cannot be generalized to longer times after exercises and possible late hypoglycemias or hyperglycemias. More adequate BMI Z-score indices were associated with better metabolic control assessed through the Hba1c.

\section{Acknowledgements}

Authors would like to thank the Conselho Nacional de Desenvolvimento Científico e Tecnológico (CNPq - National Council for Scientific and Technological Development) and Coodenação de Aperfeiçoamento de Pessoal de Nível Superior (CAPES - Coordination for the Improvement of Higher Education Personnel) for the financial support and scholarships granted. 


\section{Author's contribution}

V. A Lima (0000-0002-9413-4645) research data collection, article writing. L. P. G Mascarenhas (0000-0002-7762-2727) research data collection, article review.

J. P Decimo (0000-0002-4132-8809) research data collection, article review. W. C Souza (0000-0002-1585-0353) article review. S. N França (0000-0002-3987-3998) article review. N. Leite (0000-0002-4752-6697) research supervisor.

\section{Conflict of interest}

There is no conflict of interest

\section{References}

1. De Angelis K, Pureza DY, Flores LJF, Rodrigues B, Melo KFS, SchaanBD et al. Physiological Effects of Physical Training in Patients with Type 1 Diabetes. Arq Bras Endocrinol Metab. 2006; 50:6.

2. Yardley JE, Hay J, Abou-Setta AM, Marks SD, McGavock J. A systematic review and metaanalysis of exercise interventions in adults with type 1 diabetes. Diabetes Res Clin Pract. 2014; 106(3):393-400.

3. Inzucchi, SE, Bergenstal RM, Buse JB, Diamant M, Ferrannini E, Nauck $M$ et al. Management of Hyperglycemia in Type 2 Diabetes: A Patient-Centered Approach Position Statement of the American Diabetes Association (ADA) and the European Association for the Study of Diabetes (EASD). Diabetes Care. 2012; 35(6):1364-79.

4. Barbero-Álvarez JC, D’Ottavio S, Granda VJ, Castagna C. Aerobic fitness in futsal players of different. J Strength Cond Res, Champaign. 2009; 23(7): 2163-66

5. Oliveira PR. Particularities of motor actions and metabolic characteristics of specific efforts of women's youth and child-youth volleyball. Revista das Faculdades Claretianas. 1997:6:47-50

6. Bailey RC, Olson J, Pepper SL, Porszasz J, Barstow TJ, Cooper DM. The level and tempo of children's physical activities: an observational. Study. Med Sci Sports Exerc.1995; 1033-41.

7. Guelfi KJ, Ratnam N, Smythe GA, Jones TW, Fournier PA. Effect of intermittent high-intensity compared with continuous moderate exercise on glucose utilization in individuals with type 1 diabetes. Am J Physiol Endocrinol Metab. 2007;292:865-70.

8. Iscoe KE, Riddell MC. Continuous moderateintensity exercise with or without intermittent high-intensity work: Effects on acute and late glycaemia in athletes with Type 1 diabetes mellitus. Diabet. Med. 2011; 28(7):824-32.

9. Balke B, Ware RW. An experimental study of physical fitness of air force personnel. Forces Med Journa. 1959; 6(10):675-88.

10. Tanaka H; Monahan KD, Seals DR. Age - predicted maximal heart rate revisited. J Am Coll Cardiol. 2001; 37(1):153-6.

11. Organização Mundial da Saúde. Growth reference data for 5-19 years, WHO reference 2007.

12. Heyman E. et al. Exercise training and cardiovascular risk factors in type 1 diabetics adolescent girls. Pediatric Exerc Sci. 2007; 19:408-19.

13. Sideraviciuté $S$. et al. The effect of long-term swimming program on body composition, aerobic capacity and blood lipids in 14-19 years aged healthy girls and girls with type 1 diabetes mellitus. Medicina (Kaunas); 2006; 42(8):661-6.

14. Sociedade Brasileira de Diabetes (SBD). Clinical and laboratorial aspects of glycated hemoglobin. Diretrizes SBD. 2013-4.

15. Guelfi KJ, Jones TW, Fournier PA. The Decline in Blood Glucose Levels Is Less With Intermittent High-Intensity Compared With Moderate Exercise in Individuals With Type 1 Diabetes. Diabetes Care. 2005; 28(6):1289-94.

16. Guelfi KJ, Jones TW, Fournier PA. Intermittent High-Intensity Exercise Does Not Increase the Risk of Early Postexercise Hypoglycemia in Individuals With Type 1 Diabetes. Diabetes Care. 2005; 28(2):416-8.

17. Lima VA, Leite N, Decimo JP, Titski ACK, Souza W.C, Mascarenhas LPG. Comparison of the acute effect of continuous and intermittent aerobic training on blood glucose of 
individuals with type 1 diabetes. Rev Pesq Fisiot 2015; 5(2):102-7

18. Miller BF, Fattor JÁ, Jacobs KA, Horning MA, Navazio F, Lindinger MI et al. Lactate and glucose interactions during rest and exercise in men: effect of exogenous lactate infusion. Journal Physiol. 2002; 544:963-75.

19. Dubé MC, Lavoie C, Weisnagel SJ. Effect of intermittent high intensity exercise on counter-regulatory hormones in type 1 diabetes glargine/glulisine users. J Diab Res Clin Met. 2014; 3(8):1-5.

20. Johnson SR, Cooper MN, Davis EA, Jones TW. Hypoglycemia, fear of hypoglycemia and quality of life in children with type 1 diabetes and their parents. Diabet Med. 2013; 30:1126-31

21. Diretrizes da Sociedade Brasileira de Diabetes. Targets in Clinical and Metabolic Control of Children and Adolescents with Type 1 Diabetes. 2015-2016: 62-3

22. Nordwall M, Abrahamsson M, Dhir M, Fredrikson M, Ludvigsson J, Arnqvist H J. Impact of HbA1c, Followed From Onset of Type 1 Diabetes, on the Development of Severe Retinopathy and Nephropathy: The VISS Study (Vascular Diabetic Complications in Southeast Sweden). Diabetes Care. 2015; 38:308-15.

23. Quirk H, Blake H, Tennyson R, Randell TL, Glazebrook C. Physical activity interventions in children and adolescents with type 1 diabetes mellitus: a systematic review with metaanalysis. Diabet Med. 2014; 31(1):1.163-73.

24. Duncan B, Schimdt MI, Giuliani ERJ. Outpatient medicine: clinical conducts in primary care 2. ed. Porto Alegre: Artemed, 1996.

25. Bem AF, Kunde J. The importance of glycated hemoglobin determination in the management of chronic complications associated with diabetes mellitus. J BrasPatolMed Lab. 2006; 42(3):185-91.

26. Miculis CP, Mascarenhas LP, Boguszewski MCS, Campos W. Physical activity in children with type 1 diabetes. J Pediatr (Rio J). 2010; 86(4):271-8.

27. Sociedade Brasileira de Diabetes (SBD). How to prescribe exercises in the treatment of Diabetes Mellitus. P.246. 2015.

28. Waclawovsky G, Umpierre D, Figueira F, Lima ES, Alegretti A, et AL. Exercise on Progenitor Cells in Healthy Subjects and Patients with Type 1 Diabetes. Med Sci Sports Exerc. 2016; 48(2):190-9.

29. Corigliano G, Iazzetta N, Corigliano M, Strollo F. Blood glucose changes in diabetic children and adolescents engaged in most common sports activities," Acta Biomedica de l'ateneo parmense. 2006; 77(1):26-33.

30. Chiasson J, Aris-jilwan N, Bélanger R, Bertrand S, Beauregard H, Ekoé JM, Fournier H, Havrankova J. Diagnosis and treatment of diabetic ketoacidosis and the hyperglycemic hyperosmolar state. CMAJ, 2003; 168(7):859-66.

Corresponding

Author

Valderi Abreu de Lima

valderiabreulima@hotmail.com
Rua Arthur Virmond de Lacerda, 36

Jardim Montreal, Lapa, Paraná, Brazil

83750-000

Telephone: +554136220388
Received

$16 / 09 / 2016$

Approved $\quad 10 / 07 / 2017$ 